\title{
ARTICLE
}

\section{Estimating spatial distribution of aridity and moisture indices of Mongolia using remotely sensed time series data}

\author{
Munkhdulam Otgonbayar ${ }^{1 *}$, Erdenesukh Sumiya ${ }^{2}$ and Renchinmyadag Tovuudorj ${ }^{1}$ \\ ${ }^{1}$ Division of Physical Geography, Institute of Geography and Geoecology, \\ Mongolian Academy of Sciences, Ulaanbaatar, Mongolia. \\ ${ }^{2}$ Division of Natural Sciences, School of Arts and Sciences, \\ National University of Mongolia, Ulaanbaatar, Mongolia.
}

ARTICLE INFO: Received: 29 Nov, 2020; Accepted: 3 Mar, 2021

\begin{abstract}
The aim of this study is to estimate the spatial distribution of aridity and moisture indices using remotely sensed time-series data. For the analysis, we have chosen two simple climatic indices. One of two indices was the De Martonne aridity index, and the other one was the Mezentsev moisture index. The study area covers the total territory of Mongolia $\left(\sim 1.566 \times 10^{6} \mathrm{~km}^{2}\right)$. Both indices could be estimated from meteorological station-based air temperature and precipitation. However, meteorological station-based recorded precipitation and temperature data with long coverage are only available from a limited number of stations with insufficient spatial coverage. In other words, these datasets suffer from uneven geographic coverage, with many areas of the Earth poorly represented. In this study, therefore, we have used satellite-derived temperature and precipitation data. Monthly mean air temperature has been estimated from MODIS LSTd, LSTn, and elevation using RF regression. Precipitation data has been extracted from Climate Hazards Group Infra-Red Precipitation with Station (CHIRPS) datasets. CHIRPS is gauge-satellite combined precipitation data. Based on De Martonne and Mezensev formulas, and satellite-derived meteorological data, spatial distribution maps of aridity and moisture indices in Mongolia were generated. The study result showed that aridity was observed in all areas of southern Mongolia, and some areas in the west, and grassland areas in the east, which is largely included in the dry steppe, desert-steppe, and gobi desert zones. Moisture was observed in the forest and forest-steppe areas in north, central, northeastern, and eastern Mongolia. A comparison of the aridity index and moisture index shows the following: of the total territory, aridity is 31.9:31.4 percent, humidity 14.7:13.4 percent respectively. Dry steppe, desert steppe, and Gobi desert zones are extremely sensitive to water resource variability and availability.
\end{abstract}

Keywords: Aridity index; moisture index; satellite time-series data;

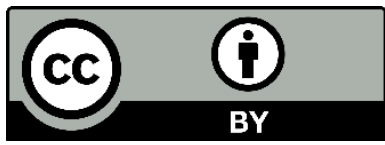

The Author(s). 2021 Open access This article is distributed under the terms of the Creative Commons Attribution 4.0 International License (https://creativecommons.org/licenses/by/4.0/), which permits unrestricted use, distribution, and reproduction in any medium, provided you give appropriate credit to the original author(s) and the source, provide a link to the Creative Commons license, and indicate if changes were made. 


\section{INTRODUCTION}

The climate is a natural resource serving as a basis for many kinds of socio-economic activities. Applied classification of climate, focused on concrete needs of economics and social life, are considered. The ecological potential of landscape (eco-potential) or the ability to quantify ecological resources based on climatic variables [1] are referred to in classical natural science publications [2-13]. On the other hand, climate resource is the main indicator of nature-ecology that determines a nation's economic sector and its development [14]. Various climatic indices are widely used to perceive climate mechanisms, and assess climatic conditions [15]. The use the aridity or humidity index to assess the territory from a climatic point of view [16-17] is considered to be significantly important. An aridity index is a numerical indicator of the degree of dryness of the climate at a given location [18]. Aridity is the degree to which a climate lacks moisture to sustain life in terrestrial ecosystems, and is the opposite of humidity [19-20]. Several recent studies, using the aridity index, have concluded that aridity will increase with $\mathrm{CO}_{2}$ because of increasing temperature [21]. Over the past period, several researchers have estimated the spatial distribution and spatial-temporal change in the aridity of Mongolia, using the meteorological station-measured temperature and precipitation data based on aridity equations. For instance, Nyamtseren, Feng, Deo [22] estimated spatiotemporal variations of four different indices over Mongolia, using climatic data from 70 weather stations for the period 1961-2015. Two of the four indices were de Martonne aridity index and moisture coefficient by Mezentsev. The results showed that about 25.5 percent and 29.1 percent of the entire area is classified as arid climate by the de Martonne aridity and Mezentsev moisture indices, respectively. Munkhdulam, Avirmed, and Sainbayar [23] also estimated spatial distribution of three different indices: hydrothermal coefficient by Selyaninov, biological effectiveness index by Ivanov, and bioclimatic potential by Shashko over Mongolia using climatic data from some meteorological stations and posts, land surface temperature of the MODIS (Moderate Resolution Imaging Spectroradiometer), and precipitation data of the TRMM (Tropical Rainfall Measure Mission) for the period 20002014. Natsagdorj, Munkhbat, and Gomboluudev [24] have assessed of the soil moisture supply using annual precipitation, Shashko's humidity coefficient, Selyainov's heat-moisture coefficient and IvanovMezentsev climate biological productivity index. In this study we have estimated the long term trends of these indices. The aim of this study is to estimate the spatial distribution of aridity and moisture indices using remotely sensed time-series data.

\section{Study area}

The study area covers the total territory of Mongolia $\left(\sim 1.566 \times 10^{6} \mathrm{~km}^{2}\right)$. The land surface elevation fluctuates between $524 \mathrm{~m}$ and $4320 \mathrm{~m}$ above sea level, gradually increasing from east to west (Figure 1). 83.7 percent of the total area of Mongolia is located at an elevation of higher than $1000 \mathrm{~m}$, which is one of the reasons for the temperate climate. Climate conditions are continental, with Mongolia being a semiarid and arid region distinguished by a long, cold winter and dry, hot summer, low precipitation, and an average of 260 sunny days per year. The average temperature ranges from $-8^{\circ} \mathrm{C}$ to $+6^{\circ} \mathrm{C}$ with strong temperature gradients. Total annual precipitation ranges from $50 \mathrm{~mm}$ in the desert regions to $500 \mathrm{~mm}$ in the high mountain areas. Spatial variation gradually increases from south to north. 


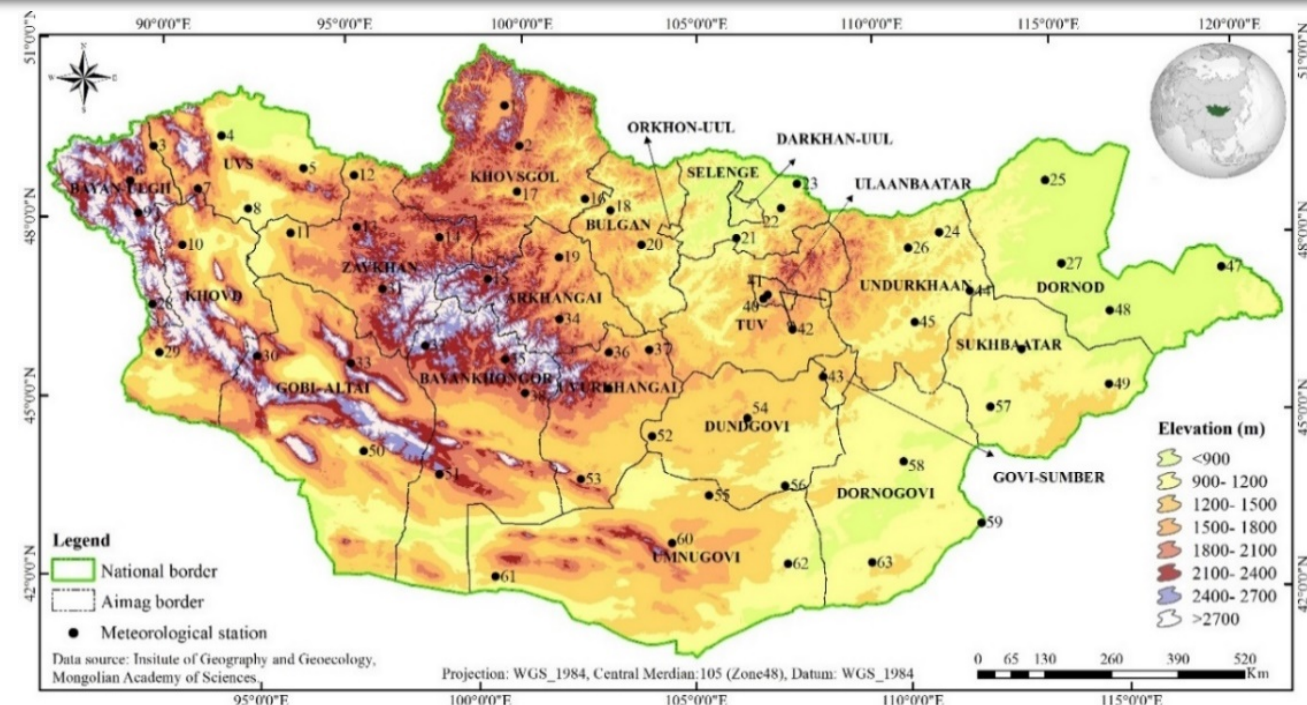

Figure 1. Study area with meteorological stations $(n=63)$. Elevation data extracted from the shuttle radar topography mission (SRTM) digital elevation model (DEM) with a resolution of $90 \mathrm{~m}$

\section{MATERIALS AND METHODS}

\section{A. Method}

Based on literature review of international and national research, we have chosen two climatic indices. One of two indices was the De Martonne aridity index, and the second one was the Mezentsev moisture index.

\section{De Martonne (1925) aridity index [25]}

In this study, we have chosen the De Martonne aridity index (Iar). In the first half of the past century, the index was developed by the French researcher Emmanuelde Martonne [26]. It is one of the oldest aridity indices and it has still been widely used in climatology because of its efficiency and relevance concerning arid/humid climate classification [27-30]. The index may be calculated both on an annual and on a shorter period basis. The annual value of the De Martonne aridity index is calculated as in the below Equation (1).

$$
I_{\text {ar }}=\frac{P}{T+10}
$$

Where

$I_{a r}-$ De Martonne aridity index $\left(\mathrm{mm} /{ }^{\circ} \mathrm{C}\right)$

$P$ - The sum of annual precipitation (mm)

$T$ - The annual mean air temperature (oC)

For seasonal aridity, the index was calculated as in Equation (2).

Where

$$
I_{a r}=\frac{4 P_{s}}{T_{a s}+10}
$$
$(\mathrm{mm})$

$P_{S}-$ The sum of seasonal precipitation

$T_{a s}$ - The seasonal mean air temperature (oC) for the analyzed season.

The monthly value of the De Martonne aridity index calculated as in Equation (3) [31]

Where

$$
I_{\text {ar }}=\frac{12 P^{\prime}}{T^{\prime}+10}
$$

$(\mathrm{mm})$

$P^{\prime}-$ The sum of monthly precipitation

$T^{\prime}-$ The monthly mean air temperature.

Table 1. Climate classification of aridity based on De Martonne equation [31]

\begin{tabular}{lc}
\hline Climate type & $I_{a r}$ value \\
\hline Arid & $\leq 10$ \\
Semi-arid & $10-20$ \\
Mediterranean & $20-24$ \\
Semi-humid & $24-28$ \\
Humid & $28-35$ \\
Very humid & $35-55$ \\
Extremely humid & $\geq 55$ \\
\hline
\end{tabular}




\section{Mezentsev (1969) moisture index [32]}

The moisture index was developed by a Russian scientist Mezentsev in 1955 [33]. Mezentsev and Karnatsevich [32] proposed to apply the runoff constant to define the climatic humidity in regions with a low density of hydrological network [22].

$$
M I=\frac{P}{\left[0.2 \sum T_{>10^{\circ} C}+306\right]}
$$

$P$ - The sum of annual precipitation ( $\mathrm{mm}$ )

$T_{>10^{\circ} \mathrm{C}}-$ The sum of the mean temperature above $10^{\circ} \mathrm{C}$

Table 2. Climate classification of humidity based on Mezentsev equation [34]

\begin{tabular}{llc}
\hline Climate type & Moisture type & MI value \\
\hline \multirow{3}{*}{ Arid } & Insignificant moisture & $<0.2$ \\
& Poor moisture & $0.2-0.3$ \\
& Low moisture & $0.3-0.4$ \\
\hline \multirow{3}{*}{ Dry and insufficient moisture } & Insufficient moisture & $0.4-0.5$ \\
& Irregular moisture & $0.5-0.8$ \\
& Moderate moisture & $0.8-1.0$ \\
\hline \multirow{3}{*}{ Humid and high humid } & Sufficient moisture & $1.0-1.2$ \\
& Moderately high moisture & $1.2-1.5$ \\
& High moisture & $1.5-2.0$ \\
\hline Extra humid & Excess moisture & $>2.0$ \\
\hline
\end{tabular}

\section{B. Data}

In this study, we used two kinds of meteorological data, namely, air temperature and precipitation.

\section{Air temperature}

Direct measurements of air temperature at a height of $2 \mathrm{~m}$ above ground are only available from a limited number of meteorological stations. In Mongolia, the spatial coverage of these measurements is inadequate. On the contrary, satellite-derived land surface temperature (LST) data are continuous in both spatial-temporal coverage and are relatively inexpensive. However, the satellite does not directly measure Ta but only the LST. In this study, we used estimated air temperature data from satellite-derived land surface temperature (LST) (Figure 2) [33].

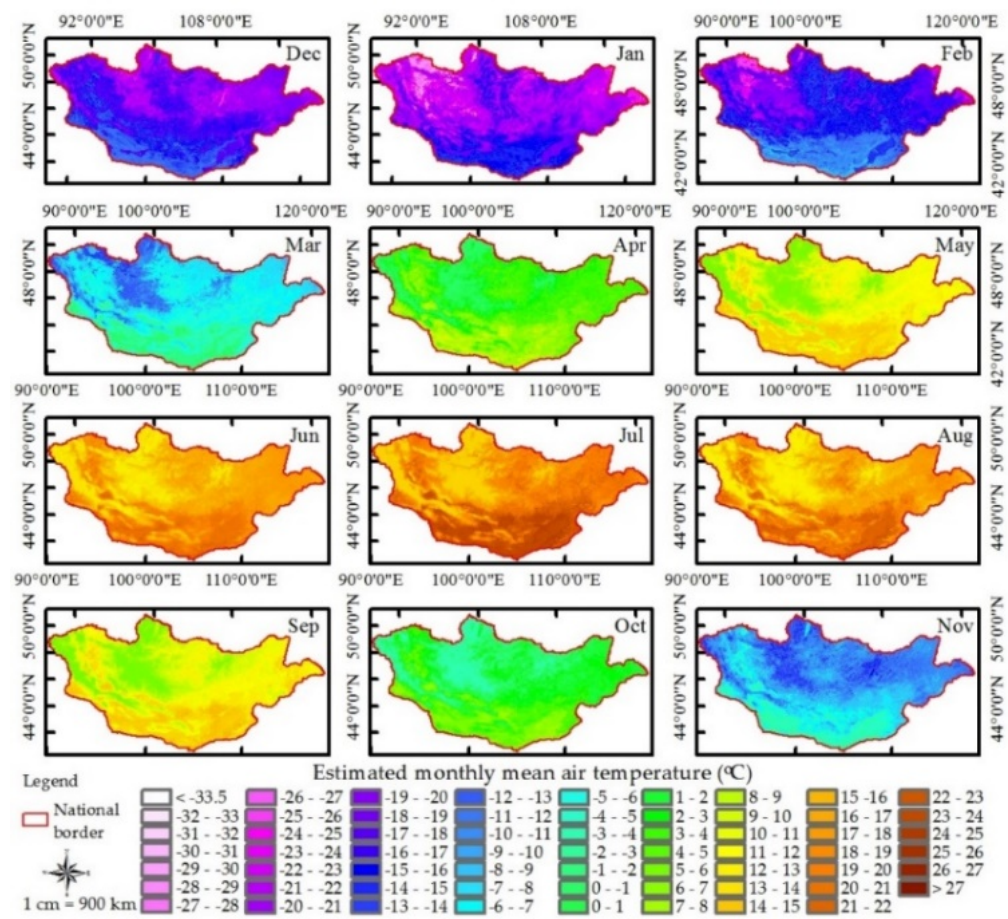

Figure 2. Estimated monthly mean air temperature over Mongolia for the period 2002-2017, based on RF regression model using LSTd, LSTn, and elevation as predictor variables at $1 \mathrm{~km}$ spatial resolution [35] 
Otgonbayar et al [35] developed a statistical model to estimate monthly average near-surface air temperature over Mongolia, based on Random Forest (RF) regression model using a Moderate Resolution Imaging Spectroradiometer (MODIS) day-time LST (LSTd), night-time LST (LSTn), and elevation.

\section{Precipitation data}

Accurate estimates of precipitation (e.g. spatial distribution, amounts, and intensity) are vitally important components of the global hydrological cycle, and their spatiotemporal variability directly affects regional water resources. However, the properties of precipitation and the limitations of the observing system make quality estimates of the precipitation challenging. Precipitation is mainly measured with three methods, which are the gauge, weather radar, and remote sensing (see, Figure 3).
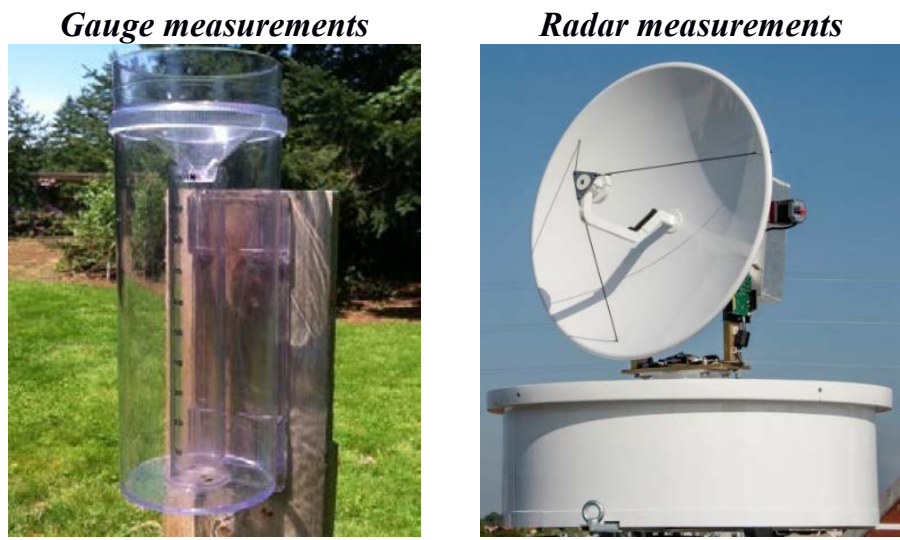

\section{Satellite sensor measurements}

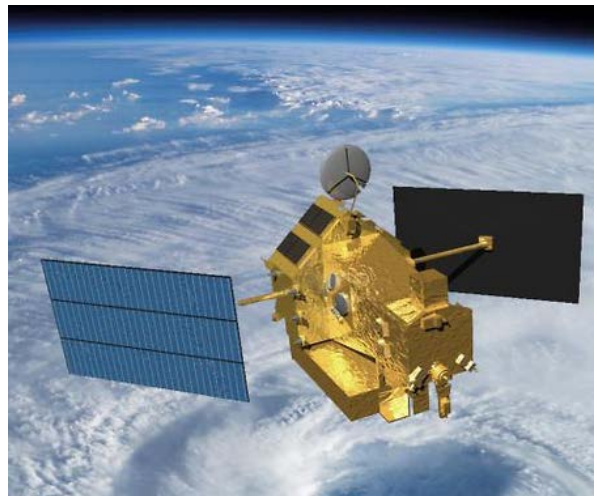

Figure 3. Three instruments for precipitation measurement

In other words, all precipitation data sets around the world can be divided into three groups: gauge datasets, satellite-based datasets, and harmonized gauge-satellite products [36]. In these three schemes individual advantages and disadvantages have been observed. Gauge measurements are used to directly estimate the point precipitation at the land surface, determining the total amount of rainfall with high quantitative accuracy as it accumulates over time. However, gauge measurements have several drawbacks, such as large areas without ground observation stations (coarse spatial coverage), a high proportion of missing data, and short length records. Wind and evaporation also affect gauge measurements. Measurements of weather radar provide reasonable spatial coverage of precipitation for a large area of up to $\sim 300 \mathrm{~km}$ from the radar site. However, in radar precipitation, measurements also have several limitations including ground clutter, beam height alteration, and beam blockage by mountains and high buildings.
Precipitation data derived from satellites can potentially beat the issues of data scarcity caused by loose rain gauges. But at most, satellites pass over a region twice a day-even with the near-global coverage of satellitespotentially missing precipitation events.

In this study, we used precipitation extracted from Climate Hazards Group InfraRed Precipitation with Station (CHIRPS) data. CHIRPS data was overall far more accurate than other precipitation. CHIRPS is a gauge-satellite combined precipitation data at a spatial resolution of $1 \mathrm{~km}$. The disadvantage of the CHIRPS data is its limited spatial coverage. Indeed, CHIRPS only covers the area $50 \mathrm{~S}^{\circ}$ $50 \mathrm{~N}^{\circ}$ whereas the northern part of Mongolia goes up to $52 \mathrm{~N}^{\circ}$. To generate a gap-free wallto-wall map for the entire territory of Mongolia, we filled the part of Mongolia between $50^{\circ} \mathrm{N}$ and $52^{\circ} \mathrm{N}$ with data from the Climate Hazards Center's Precipitation Climatology data version 1.0 (Figure 4). 

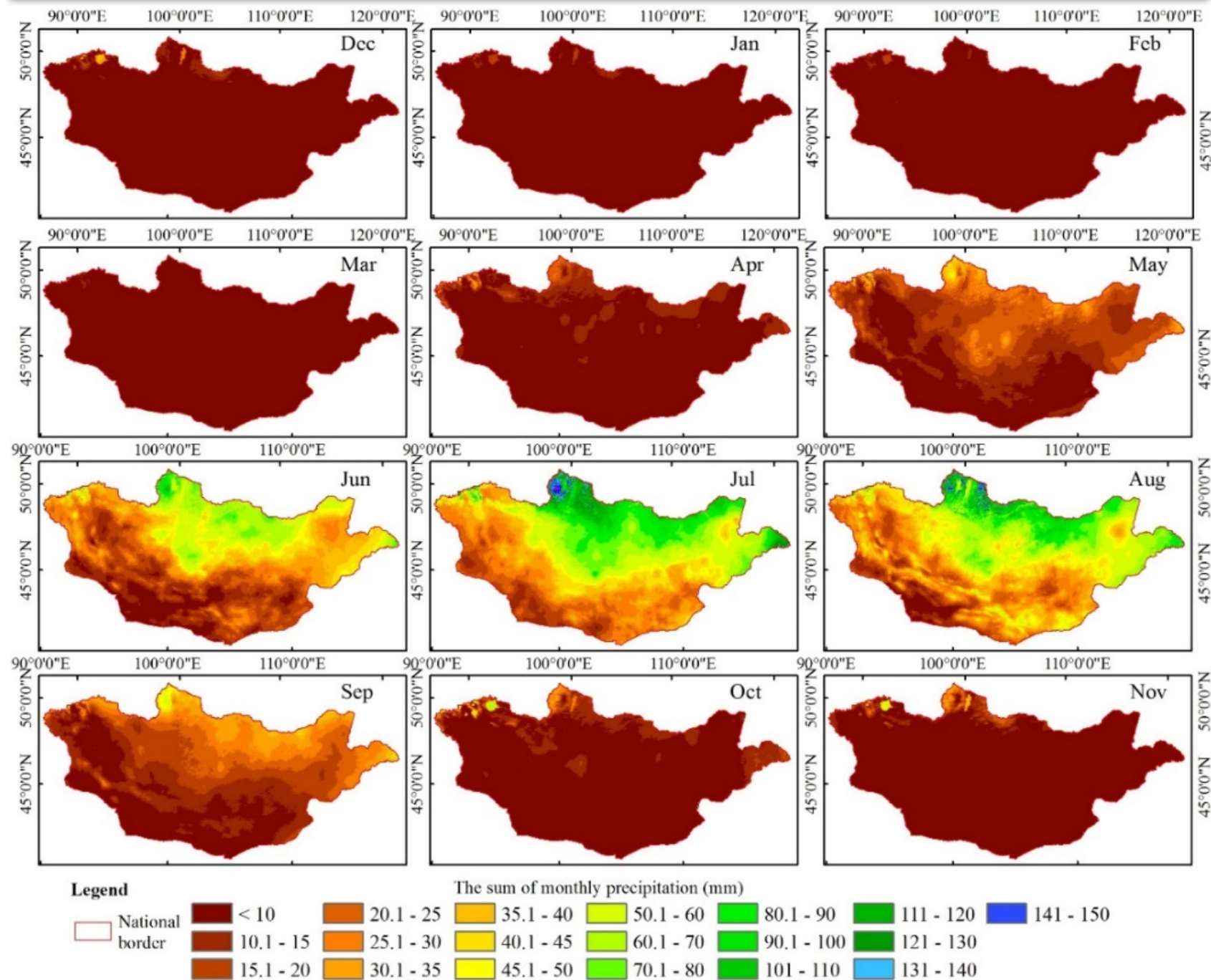

The sum of monthly precipitation ( $\mathrm{mm}$ )
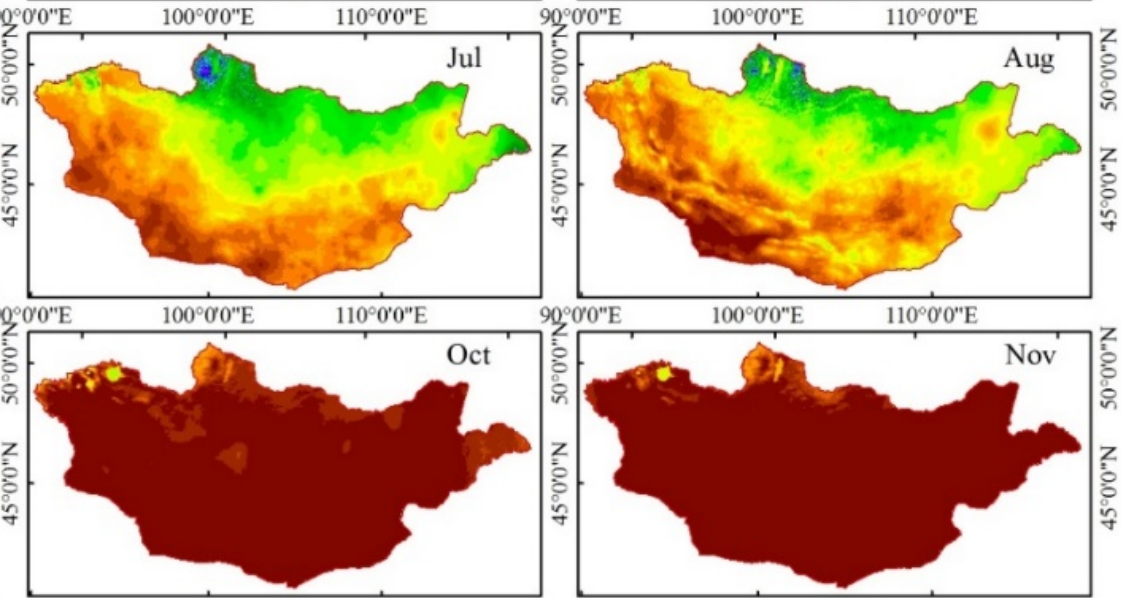

Figure 4. The sum of monthly precipitation extracted from CHRIPS for the period 2002-2017

\section{RESULTS AND DISCUSSION}

In this paper, we have estimated spatial distribution aridity and moisture indices over Mongolia derived from satellite-based time series temperature and precipitation data for the period 2002-2017. The spatial distribution map of De Martonne aridity index over Mongolia has been shown in Figure 5. The study result showed that 31.9 percent of the study area is arid, 22.6 percent semiarid, 18.6 percent Mediterranean, 11.9 percent semi-humid, 8.1 per cent humid, 2.9 percent very humid, 3.7 percent extremely humid (Table 3 ). 


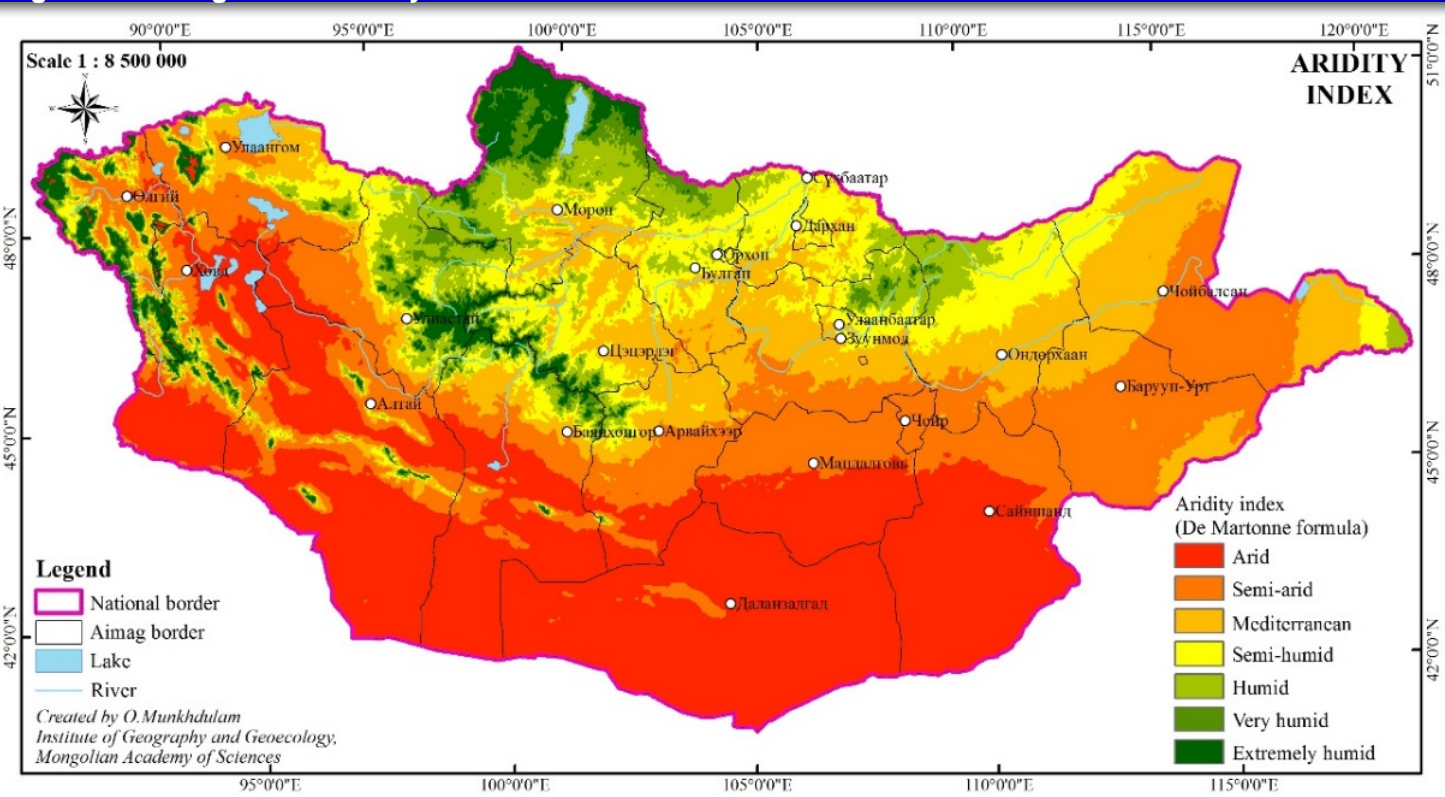

Figure 5. Spatial distribution map of aridity index over Mongolia for the period 2002-2017

Table 3. Climate classification of aridity based on De Martonne equation [31]

\begin{tabular}{lccc}
\hline \multirow{2}{*}{ Climate type } & $I_{\text {ar }}$ value & \multicolumn{2}{c}{ Area } \\
\cline { 3 - 4 } & & $\mathrm{Km}^{2}$ & $\%$ \\
\hline Arid & $\leq 10$ & 499711 & 31.9 \\
Semi-arid & $10-20$ & 358031 & 22.9 \\
Mediterranean & $20-24$ & 290412 & 18.6 \\
Semi-humid & $24-28$ & 186364 & 11.9 \\
Humid & $28-35$ & 126321 & 8.1 \\
Very humid & $35-55$ & 44634 & 2.9 \\
Extremely humid & $\geq 55$ & 58642 & 3.7 \\
\hline
\end{tabular}

The spatial distribution map of Mezentsev moisture index over Mongolia is shown in Figure 6. The study result showed that 31.4 percent of the study area is arid, 55.3 percent dry (fluctuation from insufficient moisture to moderate moisture), 13.6 percent humid or fluctuation from sufficient moisture to high moisture (Table 4).

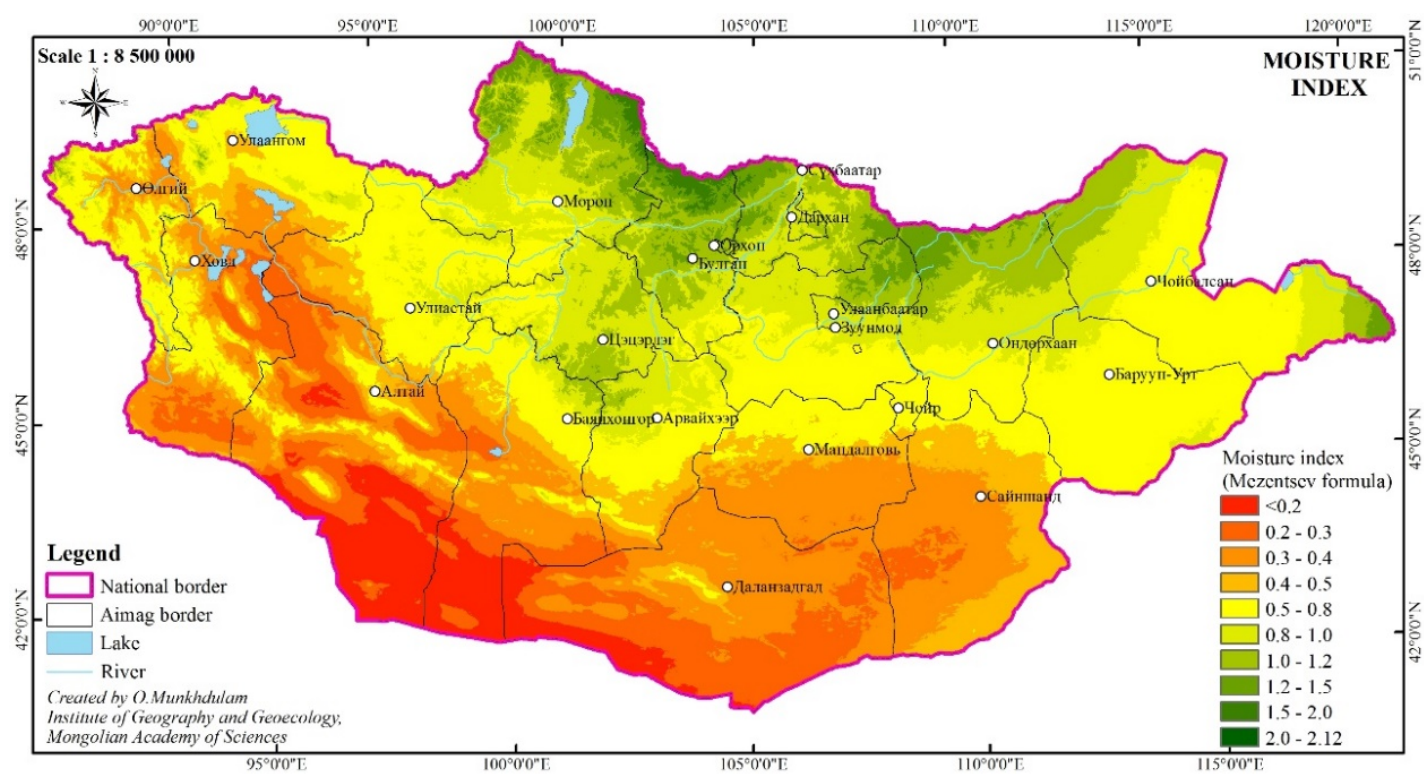

Figure 6. Spatial distribution map of moisture index over Mongolia for the period 2002-2017 
Table 4. Climate classification of humidity based on Mezentsev equation [34]

\begin{tabular}{llccc}
\hline \multirow{2}{*}{ Climate type } & \multirow{2}{*}{ Moisture type } & MI value & \multicolumn{2}{c}{ Area } \\
\cline { 3 - 5 } & & & $\mathrm{Km}^{2}$ & \multicolumn{2}{c}{$\%$} \\
\hline \multirow{3}{*}{ Arid } & Insignificant moisture & 0.2 & 74775.7 & 4.8 \\
& Poor moisture & $0.2-0.3$ & 141660.2 & 9.1 \\
& Low moisture & $0.3-0.4$ & 273350.5 & 17.5 \\
\hline \multirow{2}{*}{ Dry and insufficient } & Insufficient moisture & $0.4-0.5$ & 154277.8 & 9.9 \\
moisture & Irregular moisture & $0.5-0.8$ & 462544.9 & 29.4 \\
& Moderate moisture & $0.8-1.0$ & 249917.3 & 16.0 \\
\hline \multirow{3}{*}{ Humid and high humid } & Sufficient moisture & $1.0-1.2$ & 145615.8 & 9.3 \\
& Moderately high moisture & $1.2-1.5$ & 52472.6 & 3.4 \\
& High moisture & $1.5-2.0$ & 9451.1 & 0.6 \\
\hline Extra humid & Excess moisture & $>2.0$ & 50.1 & 0.0 \\
\hline
\end{tabular}

The study result showed that aridity was observed in all areas of southern Mongolia, and some parts in the west and grassland areas in the east, which is largely included in the dry steppe, desert-steppe, and gobi desert zones. Moisture was observed in the forest and forest-steppe zones in the north, central, northeastern, and eastern Mongolia. Compared A comparison of the aridity and moisture index revealed the following: 31.9:31.4 percent arid, 14.7:13.4 percent humid of the total territory, respectively. Dry steppe, desert steppe, and gobi desert zones are extremely sensitive to water resource variability and availability.

Nyamtseren, Feng, Deo [22] estimated spatiotemporal variations of four different indices over Mongolia using climatic data from 70 weather stations. Two of the four indices were de Martonne aridity index and moisture coefficient by Mezentsev. The results showed that about 25.5 percent and 29.1 percent of the entire area is classified as arid climate by de

\section{CONCLUSIONS}

In this study, the widely used two simple indices were applied to estimate the aridity and moisture condition of Mongolia. In order to estimate the spatial distribution of aridity and moisture indices, we used the De Martonne and the Mezentsev formulas. Both indices could be estimated from meteorological station-based air temperature and precipitation. However, meteorological station-based recorded precipitation and temperature data with long coverage are only available from a limited
Martonne aridity and Mezentsev moisture indices for the period 1961-2015, respectively. Nyantseren [22] has also illustrated the trend of these four different indices using the MannKendall test. The results indicated that in the central, northern, and northeastern parts of Mongolia there was a decreasing tendency for the period 1961-2015.

Our study results showed that about 31.9 percent and 31.4 percent of the entire area is classified as arid climate by de Martonne aridity and Mezentsev moisture indices for the period 2002-2017, respectively. Comparison result showed that de Martonne aridity index is slightly less successful. Mezentsev moisture index gave similar results. Therefore, Mezentsev moisture index could be useful for various environmental applications. Furthermore, we will illustrate the trend of aridity and moisture indices using the Sen Slope test.

number of stations with insufficient spatial coverage [35]. In other words, these datasets suffer from uneven geographic coverage, with many areas of the Earth poorly represented [37]. Therefore, we used satellite-derived temperature and precipitation data. Monthly mean air temperature was estimated from MODIS LSTd, LSTn, and elevation using RF regression [35]. Precipitation data were extracted from CHIRPS datasets. CHIRPS is a gauge-satellite combined precipitation data. 
Based on De Martonne and Mezensev formulas, and satellite-derived meteorological data, spatial distribution maps of aridity and moisture indices in Mongolia were generated. Those maps were produced at a resolution of 1 $\mathrm{km}$ for the period 2002-2017. Here, we estimated the spatial distribution of the annual aridity and moisture indices. Furthermore, we will estimate the spatial distribution of monthly, and seasonal aridity indices using Equation 2-3.

Acknowledgements. In 2017-2019, the Division of Physical Geography, Institute of
Geography and Geoecology (IGG), Mongolian Academy of Sciences (MAS) implemented the "Assessment of landscape ecological potential of Mongolian natural zones" project funded by the Mongolian Foundation for Science and Technology. This research work was carried out under this project. The authors would like to thank the project leader Dr. E. Avirmed, and all colleagues at the IGG, MAS, and Department of Geography, National University of Mongolia for their invaluable help in this research.

\section{REFERENCES}

1. Parfenova, E., Tchebakova, N. and Soja, A., 2019. Assessing landscape potential for human sustainability and 'attractiveness' across Asian Russia in a warmer $21^{\text {st }}$ century. Environmental Research Letters, 14(6), p. 065004.

2. Dokuchaev, V.V. and Sibirtsev, N.M., 1893. Short scientific review of Professor Dokuchaev's and his pupil's collection of soils exposed in Chicago in the year 1893. E. Evdokimova, St. Petersburg, Russia.

3. Clements, F.E., 1907. Plant physiology and ecology. $\mathrm{H}$. Holt.

4. Gleason, H.A., 1925. Species and area. Ecology, 6(1), pp. 66-74.

5. Sukachev, V.N., and Dylis, N.V., 1964. Fundamentals of Forest Biogeocoenology

6. Holdridge, L.R., 1947. Determination of world plant formations from simple climatic data. Science, 105(2727), pp. 367368.

7. Tansley, A.G., 1947. The early history of modern plant ecology in Britain. Journal of Ecology, 35(1/2), pp. 130-137.

8. Grigoriev, A.A. and Budyko, M.I., 1956. About the periodic law of geographical ash value. Reports Acad. Sci. USSR, 110(1), pp. 129-132.

9. Whittaker, R.H., 1970. Communities and ecosystems. Communities and ecosystems.

10. Budyko, M.I., 1974. Climate and life. Academic Press, Inc..

11. Mirkin, B.M., 1987. Paradigm change and vegetation classification in Soviet phytocoenology. Vegetatio, 68(3), pp. 131138.
12. Odum, E.P. and Barrett, G.W., 1971. Fundamentals of ecology (Vol. 3, p. 5). Philadelphia: Saunders.

13. Isachenko, A.G., 2003. Introduction to ecological geography. Manual. SPb.: Publishing house of the Petersburg university.

14. Mijiddorj, J., 2016. Climate change and its impact on agriculture, food security. Mongolian Journal of Agricultural Sciences, 14(1), pp. 251-257.

15. Deniz, A., Toros, H. and Incecik, S., 2011. Spatial variations of climate indices in Turkey. International Journal of climatology, 31(3), pp. 394-403.

16. Pellicone, G., Caloiero, T. and Guagliardi, I., 2019. The De Martonne aridity index in Calabria (Southern Italy). Journal of Maps, 15(2), pp. 788-796.

17. Kafle, H.K. and Bruins, H.J., 2009. Climatic trends in Israel 1970-2002: warmer and increasing aridity inland. Climatic Change, 96(1-2), pp. 63-77.

18. Moral, F.J., Rebollo, F.J., Paniagua, L.L., García-Martín, A. and Honorio, F., 2016. Spatial distribution and comparison of aridity indices in Extremadura, southwestern Spain. Theoretical and Applied Climatology, 126(3-4), pp. 801814.

19. American Meteorological Society, 2006. Glossary of Meteorology

20. Mandakh, N. and Batomunkuev, V.S., 2017. Changes of aridity indices in Mongolia. Bulletin of the Buryat State 
University. Biology, geography (4), pp. 8390.

21. Greve, P., Roderick, M.L. and Seneviratne, S.I., 2017. Simulated changes in aridity from the last glacial maximum to $4 \mathrm{xCO} 2$. Environmental Research Letters, 12(11), p. 114021.

22. Nyamtseren, M., Feng, Q. and Deo, R., 2018. A comparative study of temperature and precipitation-based aridity indices and their trends in Mongolia. International Journal of Environmental Research, 12(6), pp. 887-899.

23. Munkhdulam, O., Avirmed, E., Sainbayar, D. 2017. Assessment bio-climate potential of Mongolia based on the satellite image and meteorological observation data. Proceedings of the Mongolian Academy of Sciences, pp. 5-20.

24. Natsagdorj, L., Munkhbat, B., Gomboluudev, P. 2019. Climate biocapacity of Mongolia and its change. Proceedings of the Mongolian Academy of Sciences, pp. 54-70.

25. De Martonne E (1925) Traité de Géographie Physique. 3 tomes. Paris.

26. Coscarelli, R.O.B.E.R.T.O., Gaudio, R.O.B.E.R.T.O. and Caloiero, T., 2004. Climatic trends: an investigation for a Calabrian basin (southern Italy). IAHS PUBLICATION, 286, pp. 255-266.

27. Baltas, E., 2007. Spatial distribution of climatic indices in northern Greece. Meteorological Applications: A journal of forecasting, practical applications, training techniques and modelling, 14(1), pp. 69-78.

28. Shahid, S., 2010. Spatio-temporal variation of aridity and dry period in term of irrigation demand in Bangladesh. American-Eurasian J Agric Environ Sci, 7(4), pp. 386-396.

29. Zarghami, M., Abdi, A., Babaeian, I., Hassanzadeh, Y. and Kanani, R., 2011. Impacts of climate change on runoffs in
East Azerbaijan, Iran. Global and Planetary Change, 78(3-4), pp. 137-146.

30. Adnan, S. and Haider, S., 2012. Classification and assessment of aridity in Pakistan by using different aridity indices. Retrieved on, 10(12), p. 2016.

31. Croitoru, A.E., Piticar, A., Imbroane, A.M. and Burada, D.C., 2013. Spatiotemporal distribution of aridity indices based on temperature and precipitation in the extraCarpathian regions of Romania. Theoretical and applied climatology, 112(3-4), pp. 597-607.

32. Mezentsev, V.S. and Karnatsevich, I.V., 1969. Humidity of western Siberian plain. Leningrad: Gydrometizdat (in Russian).

33. Mezentsev, V., 1955. Back to the computation of total evaporation. Meteorologia i Gidrologia, 5, pp. 24-26.

34. Ivanov, N.N., 1948. Landscape-climatic zones of the earth surface. In Proceedings, All Soviet Geographical Conference, New Series (Vol. 1). Publication of the Academy of Sciences of the USSR Leningrad.

35. Otgonbayar, M., Atzberger, C., Mattiuzzi, M. and Erdenedalai, A., 2019. Estimation of Climatologies of Average Monthly Air Temperature over Mongolia Using MODIS Land Surface Temperature (LST) Time Series and Machine Learning Techniques. Remote Sensing, 11(21), p. 2588.

36. Funk, C., Verdin, A., Michaelsen, J., Peterson, P., Pedreros, D. and Husak, G., 2015. A global satellite assisted precipitation climatology. Earth System Science Data Discussions, 8(1).

37. Hijmans, R.J., Cameron, S.E., Parra, J.L., Jones, P.G. and Jarvis, A., 2005. Very high resolution interpolated climate surfaces for global land areas. International Journal of Climatology: A Journal of the Royal Meteorological Society, 25(15), pp. 19651978. 